\title{
Discussion on status and prospect of college physical education reform from human-oriented view
}

\author{
Hongchun Jia \\ School of Physical Education, Beihua University, Jilin Jilin, 132021,China
}

Keywords: Human-oriented cause, College physical education, Education reform.

\begin{abstract}
. with the development of the time, college physical education has attracted great attention as it has the function of building up students' physical condition and improve their physical quality. But in college physical education reform work from human-oriented view, there frequently appear some problem influencing education efficiency so that they cannot improve the human-oriented education, the reform work is not well completed, and system is short of efficiency. This is harmful for the development. This article makes analysis on the college physical education reform status from human oriented view and proposes some countermeasures for the reference for college physical teachers.
\end{abstract}

\section{Introduction}

Currently, China has usually faced up to many difficult situation in the process of college physical education reform so that the reform of college physical education cannot be conducted effectively. However, compared with physical education in middle and primary school, college physical education has certain advantages as they cannot only independently select the physical education course content but can also reasonably control the course duration so as to make up the shortage of physical education and help the implementation of human-oriented teaching.

\section{Connotation of human-oriented physical education}

Human-oriented physical education refers to coordinate the relationship between physical skills with students according to human's unique nature so that they can help students develop based on their requirements. The most important thing in human-oriented physical education is to respect students' human nature and conduct caring education for students for educational teaching work with the fundamental starting point of human nature. That is to say, integrate physical education content, educational methods, teaching attitude and concepts together with student's nature as the teaching foundation and to design teaching contents based on their features. During the process of implementing physical education, correlate student's growth rule so as to promote their comprehensive development.

Human-oriented education pays attention to human-oriented teaching concept and uses students' independence and characteristic development features to improve teaching methods based on the analysis on students' nature and internal demands so as to establish correct teaching concept. In this way, it can develop and expand human-oriented teaching but can also effectively improve students' comprehensive quality, which is of great significance for students' growth. But human-oriented physical education refer to fully focus on college students in the whole physical education, pay attention to the excavation of students' physical potential, reasonably set physical course system, teaching method, teaching evaluation system through fully considering human-oriented control on each procedure, and abandon traditional filling-up teaching and graffiti teaching method through innovating teaching method and establishing human-oriented teaching belief so as to provide 
harmonious physical educational atmosphere, and set physical education projects suitable for developing their physical quality and each fitness training based on the analysis on different students' condition and physical ability, and then integrate the education of respecting students' freedom, self-esteem and values so as to lay solid foundation for the development of students' comprehensive qualities[1].

\section{Problems existing in Chinese college physical education}

So far, there exist some problems in the development of Chinese college physical education so as to they cannot effectively development college students' physical quality and cannot set physical exercise projects for students based on the human-oriented teaching requirement. Problems in college physical education reform include aspects as below:

\section{Teachers' quality is poor}

Before implementation of human-oriented physical education in Chinese colleges, physical education is in the process of continuous improvement and exploration with no awareness of the importance of human-oriented teaching concept. Most physical teachers still use traditional teaching modes during the teaching process with single education system and usually use rigid teaching methods for education work without setting the human-oriented teaching tart and no clear human-oriented teaching concept. Meanwhile, Chinse college physical teachers do not realize the importance of their own professional qualities. They are satisfied with the current situation and cannot continue learning physical knowledge during working. The problem is harmful for carrying out human-oriented teaching concept. Thus, there still exist gaps with national modern education concept in college physical education. During the process, college physical teachers as the guide of teaching activities, if they cannot establish correct teaching concept, physical education will be weakened so that the teaching effect will reduce [2].

\section{Problem existing in actual teaching}

With the national reform on college physical education, although some achievements have been made seemingly making human-oriented physical education has been accepted by many teachers and students. But in real teaching process, there are some problems of emphasizing teaching theories but neglecting specific practice. This will lead to many issues in Chinese college physical educational practice and influence the development of college students. Meanwhile, during class teaching process, teachers still use traditional teaching methods and physical teaching contents are decided by teachers. In addition, Chinese college physical teachers lack good service awareness so that the dominant role of students cannot be displayed, which will be harmful for the improvement of students' physical quality [3].

\section{Current status of college physical education reform}

\section{Effect of college physical education reform}

There are some effect after human-oriented reform in college physical education as presented below: firstly, course content setting has satisfied students' individual development requirement. After China issued new teaching programs, colleges have carried out different physical courses and made effective planning on setting new course according practical condition in colleges. Some colleges have set a few physical course contents and some have set dozens. In the new courses, there are traditional track and field and gymnastics course, colleges have also introduced course with strong practicability such as calisthenics and gymnastics rhythmic, which can providing many shape-physique course for students. New courses also include traditional physical exercise items such as martial art, free combat and dragon dance and lion dance. For physical intelligent activities, there are Chinese chess, Go and Five-in-a-row. Fashion type activities include street dancing, roller and Taekwondo. In this way, physical exercise contents can be innovated. Also the innovation can attract 
students to participate into physical activities with unique characteristics through combining traditional and modern physical exercise forms to satisfy college students' demands for modern sports and to lay solid foundation for development. Secondly, enrich human-oriented teaching ideology. During the teaching process, college physical teachers should introduce human-oriented teaching concept with the focus on college students" development to give human-oriented, happy and lifelong education for the purpose of their health and enrichment of teaching concept. At the same time, teachers will consider physical education issue from many aspects so that physical education contents is developing in a diversified tendency with physical education regional human-oriented to pay attention to students' individual development from the aspect of their lifelong development to truly improve college students' comprehensive quality. At last, innovate teaching mode and teaching methods. With the adjustment of physical educational system in colleges, college physical teachers start establishing new educational them to make effective reform on teaching pattern and make new teaching modes such as club physical teaching mode, three-section physical education mode, layering physical education mode, integrated physical education mode, tri-base physical education mode and comprehensive physical education mode. According to the analysis on college features, flexibly use teaching methods to present the teaching characteristics. Under the guidance of human-oriented teaching concept, physical teachers update the class teaching organization method and continuously propose new teaching organizational methods for reasonable usage. At the same time, college physical teachers have also introduced modern physical education technologies such as multi-media teaching instrument to stimulate students' learning interest and to improve their activity for laying solid foundation for their development [4].

\section{Future prospects on human-oriented physical education reform in colleges}

\section{Development trend of human-oriented teaching concept}

So far, China has made great progress in social culture and economy. Each citizen should be paid attention for better promotion of human-oriented concept. For Chinese college physical education teaching, it will also be influenced by human-oriented trend and will apply the concept into educational teaching for further implantation and promotion of human-oriented teaching mode. It can be seen that, Chinese college physical teaching is presenting a developing trend of human-oriented concept so as to help students' comprehensive quality to progress in better direction.

\section{Establish complete evaluation system}

During the process of college physical education, scientific and reasonable course evaluation system is very important. Relevant management staffs must pay attention to the establishment of teaching evaluation system so that students can face up to their study attitude and improve learning activity. Meanwhile, in the physical education process, course evaluation system can start from the teaching target through inputting human-oriented teaching concept into class teaching for multi-angle evolution. College physical teachers should realize the basic difference between different students and use evaluation system to make assessment so as to help them obtain good knowledge and develop autonomous learning and exercising habits [5].

\section{Improvement measure on teaching methods}

For national college independent study platform, it can be seen that there are more and more methods of college physical education and being optimized in real teaching process. In addition to the innovation and development to physical teaching resources, Chinese colleges can add more teaching contents when carrying out physical courses so as to obtain the target of thinking questions from the angle of human-oriented teaching. Meanwhile, college physical course will be set based on students' requirement to make sure the feasibility and optimization of course system so as to satisfy student's development demands. Schools can achieve resource sharing with active physical course resources to provide more chances for students on the basis of promoting and innovating human-oriented concept 
to promote college physical teachers further explore and research physical teaching method. During the process, teachers can use situational teaching method, game teaching method and competitive teaching method for physical education. During the process, students take up the subject position and teachers play the role of guidance so as to present the importance of human-oriented concept for laying solid foundation for the development of students' physical quality.

\section{Create good teaching atmosphere}

During college physical education process, to establish human-oriented teaching concept, make sure there is intangible and tangible infrastructure for human-oriented teaching. Reasonably apply various teaching resources and fully mobilize various equipment facilities in school sports sites to optimize students' study environment. For human-oriented teaching soft environment, teachers should guide students to establish correct learning concept and form human-oriented teaching in different procedures. Meanwhile college physical teachers should form good interactive relationship with students during the teaching process and to establish equal teaching mode on the basis of communication and exchange, and when choosing teaching contents, teachers should ask for students to participate and provide some advice and suggestions to exert the advantage of human-oriented advantages. In addition, college physical teachers can guide students to physical exercise sites with better learning environment to move facilities and expand the physical exercise site so that they can truly experience relaxed teaching atmosphere and improve their physical qualities.

\section{Improve physical teachers' professional qualities}

College physical teachers' professional qualities directly decide the teaching efficiency so that as the guide of students' learning knowledge, teachers must be qualified with good service spirit and establish correct human-oriented teaching concept to guarantee students' physical quality can be improved during the teaching process. During actual instruction, teachers must clarify their own duties and pay attention to students' subject position to maintain good interactive relation with students and to call for teacher-student equality. Meanwhile, they should truly consider students' requirement in different teaching procedure and make effective reform on late-stage teaching based on students' requirement. The most critical is that teacher should have human-oriented conceit and truly understand and respect students in real teaching. They can balance the study relationship between teaching and students and satisfy students' demands from all aspects so that they can have better development. In addition, college physical teachers should take full consideration on the new teaching guidance principles and never violate the principle of physical teaching. They should abandon traditional teaching method and keep introducing new teaching technologies and communicate with other teachers on human-oriented physical teaching concept in the spare time so that they can perfect their teaching skills and improve teaching level.

\section{Conclusion}

In college physical teaching process, for better improve college students' physical qualities and cultivate modern physical talent, teachers should introduce human-oriented teaching concept and use this concept to optimize teaching mode and to create independent and equal study atmosphere. Meanwhile, to improve teachers' professional quality, colleges should provide trainings for physical teachers on professional knowledge periodically so as to help them establish human-oriented teaching concept and fully respect students' nature in the teaching process to lay foundation for students' development.

\section{Reference}

[1] Huang Min, Chen Yingjun, Li Yali. Status and prospects on college physical education reform from humanistic view, Journal of Physical Education, 2011,18(5):78-81. 
[2] An Ni. Discussion on concepts, subjects and strategies in college physical education reform based on the view of constructivism, Journal of Guangzhou Sport University, 2015,35(6):104-106,121.

[3] Liu Zhibin. Development of educational resource and college physical education reform, Journal of Sports and Science, 2012,33(2):118-120,83.

[4] Chen Yunlong, Qin Xiaoping. Seeing Chinese college physical education reform from the cultural pattern of physical education, Sports, 2014(20):10-11,35.

[5] Qian Tao. Introduction of modern new sporting events to promote college physical education reform, Journal of Liaoning Economic Management Cadre Institute, 2015(3):97-99. 